\title{
La evolución de la bóveda maya a través de la forma de las dovelas
}

\author{
Maya Vault Development \\ Through Vault Stones Shape
}

\author{
Laura Gilabert Sansalvador \\ Universitat Politècnica de València, España
}

\begin{abstract}
RESUMEN: A lo largo de un período de más de diez siglos de tradición, la bóveda maya experimentó un gran desarrollo a nivel técnico que permitió alcanzar soluciones constructivas y estructurales muy avanzadas y formas cada vez más perfeccionadas. Uno de los factores clave para observar la evolución temporal y las distintas variantes regionales de la bóveda es la forma de las dovelas. Este trabajo parte de la toma de datos en campo y el análisis comparativo de una amplia muestra de bóvedas de diferentes zonas geográficas y períodos cronológicos y, como resultado, propone una clasificación de los tipos de dovelas. El estudio de la influencia de la estereotomía en la forma de las bóvedas y el análisis de la utilización de los diferentes tipos de dovelas por zonas ofrecen nuevos datos para profundizar en la evolución tecnológica de la arquitectura maya abovedada y en las transferencias de conocimiento constructivo.
\end{abstract}

Palabras clave: Arquitectura, construcción, bóveda, mayas, dovela.

ABSTRACT: Over more than ten centuries, Maya vaults had great technical developments that allowed to achieve constructive and structural advanced systems and increasingly improved forms. One of the key factors to consider when studying its temporal evolution and the different regional variants is the stone vaults shape. This work is based on data collected during fieldwork and comparative analysis of a wide sample of vaults from different geographical zones and chronological periods, and as a result proposes a classification of the Maya stone vaults. The study of the influence of stereotomy on its form and the analysis of the use of different types of stone vaults by zones offer new data to understand the technological evolution of vaulted Maya architecture and the transfers of building knowledge.

KeYwords: Architecture, buildings, vault, Maya, stone vault. 
RECEPCIÓN: 18 de julio de 2019.

ACEPTACIÓN: 24 de agosto de 2019.

DOI: https://doi.org/10.19130/iifl.ecm.55.2020.0003

\section{Introducción}

La bóveda es uno de los elementos constructivos más característicos de la civilización maya, no sólo por su uso continuado y extensivo en todo el territorio de las tierras bajas mayas, sino también porque fue la cultura maya la que desarrolló, en mayor grado, este sistema de cubierta de fábrica de piedra en Mesoamérica.

El sistema de bóveda utilizado por los antiguos mayas se basa en la técnica constructiva de aproximación de hiladas, que consiste en disponer hiladas horizontales de piezas que vuelan una sobre la otra y van avanzando progresivamente hacia el interior del espacio hasta cerrarlo con una última losa o tapa. La estabilidad de tal sistema se basa en el correcto contrapesado de cada una de las hiladas, bien mediante su propio peso o bien con un relleno colocado en la parte posterior que contrarresta el vuelco hacia el interior de la estancia. El principio básico de esta técnica es conducir correctamente las cargas verticales hasta los apoyos y evitar los empujes horizontales. Tiene dos ventajas fundamentales: la primera es que admite dovelas sin labra, y la segunda que permite un proceso constructivo sencillo sin la necesidad de cimbras. Sin embargo, requiere de gran espesor y peso, presenta evidentes limitaciones de forma y, sobre todo, de luz o anchura del espacio que cubre. Se trata de una solución intuitiva y de sencilla puesta en obra que fue utilizada por diferentes civilizaciones antiguas mediterráneas, asiáticas y americanas (Gilabert, 2015).

\section{Origen y desarrollo de la bóveda maya}

En las construcciones mayas más primitivas, los techos de los edificios situados sobre las plataformas eran de estructura de madera y cubierta de hoja de palma (Sharer y Traxler, 2006: 215). En ocasiones se han registrado las huellas de los cuatro postes que sostenían estas cubiertas perecederas heredadas de la arquitectura doméstica, por ejemplo, en el sitio de Cuello (Gerhardt, 1988: 112114), en la subestructura del Complejo A-V de Uaxactún (Smith, 1950) o en varias subestructuras de la Acrópolis Norte de Tikal (Coe, 1990: 217). A medida que avanzó la tecnología, empezaron a construirse edificios completos de fábrica de piedra, ${ }^{1}$ en la mayoría de los casos con el sistema de muros de carga y bóvedas por aproximación.

\footnotetext{
${ }^{1}$ La construcción de edificios con cubiertas de fábrica de piedra se produce en el momento de máximo auge de la civilización maya, y el empleo del material pétreo constituye en sí mismo un recurso más para la representación del poder en la arquitectura de la élite (Miller, 1998).
} 
Las primeras edificaciones abovedadas del área maya aparecen en la zona central del Petén guatemalteco durante el periodo Preclásico Tardío (Hansen, 1998: 105). Algunas de las más antiguas registradas hasta el momento pertenecen al Grupo H de Uaxactún (Valdés, 1992; 1993) y al Grupo 5D de la Acrópolis Norte de Tikal (Hansen, 1998:102). En las excavaciones realizadas por la Universidad de Pennsylvania en este conjunto se documentaron varias cámaras funerarias excavadas en la roca y cubiertas con una hilada de piedra horizontales (Coe, 1990). Es probable que, para poder cubrir espacios más amplios sin la necesidad de contar con piezas monolíticas de grandes dimensiones, se empezaran a disponer hiladas de piedras en voladizo progresivo hasta aproximar las dos partes y poder cerrarlas con una tapa superior de menor tamaño. Existen varios ejemplos de ello en tumbas de este mismo conjunto, como los Entierros 85 y 167, datados en torno al año 75 d.C. (Coe, 1990: 806). Posiblemente de esta manera surgieron las primeras bóvedas, normalmente escalonadas y con una forma muy irregular resultante del proceso constructivo.

El sistema de bóvedas se fue optimizando y se extendió con el tiempo a la gran mayoría de los edificios construidos con fábrica, independientemente de su función y tipología arquitectónica. Se utilizó en prácticamente la totalidad de las tierras bajas mayas, manteniéndose hasta el Posclásico, por lo que tuvo una prolongada tradición constructiva de más de mil años. Un aspecto muy importante fue la utilización y el desarrollo de las argamasas de cal, que permitían soportar mayores pesos. Como veremos más adelante, la progresiva mejora de la resistencia de los rellenos permitió grandes avances en las estructuras abovedadas.

Los muros verticales se construían generalmente de fábrica de piedra con diferentes tipos de factura, como sillares o mampuestos, y en numerosas ocasiones se combinan ambos tipos en muros mixtos, compuestos por dos hojas exteriores de sillares bien labrados y un relleno interior. Sobre los muros verticales de carga apoyan las bóvedas, formadas por dos lados convergentes y simétricos que se cierran con una losa o tapa. Al igual que los muros que las sustentan, en la gran mayoría de los casos las bóvedas están construidas con una hoja exterior de piedra y un relleno interior de mampostería y argamasa de cal que funciona como contrapeso (Figura 1). A cada una de las piedras que forman el intradós de la bóveda la hemos denominado dovela, independientemente del grado de labra o de especialización que presente.

El desarrollo de la técnica de la bóveda permitió mejorar progresivamente el sistema y conseguir, en general, espacios con mayores luces y alturas, reducir el espesor de los muros y lograr superficies interiores más perfeccionadas (Figura 2). Sin embargo, en cada zona geográfica se dio el desarrollo de la tecnología constructiva en diferentes formas y grados: las características del material pétreo, los sistemas para su extracción, el desarrollo de la calidad de los morteros y los avances de la técnica estereotómica en cada área determinaron las particularidades de las bóvedas de cada región y su evolución en el tiempo, condicionando en muchos casos los rasgos arquitectónicos y estilísticos de los edificios. 


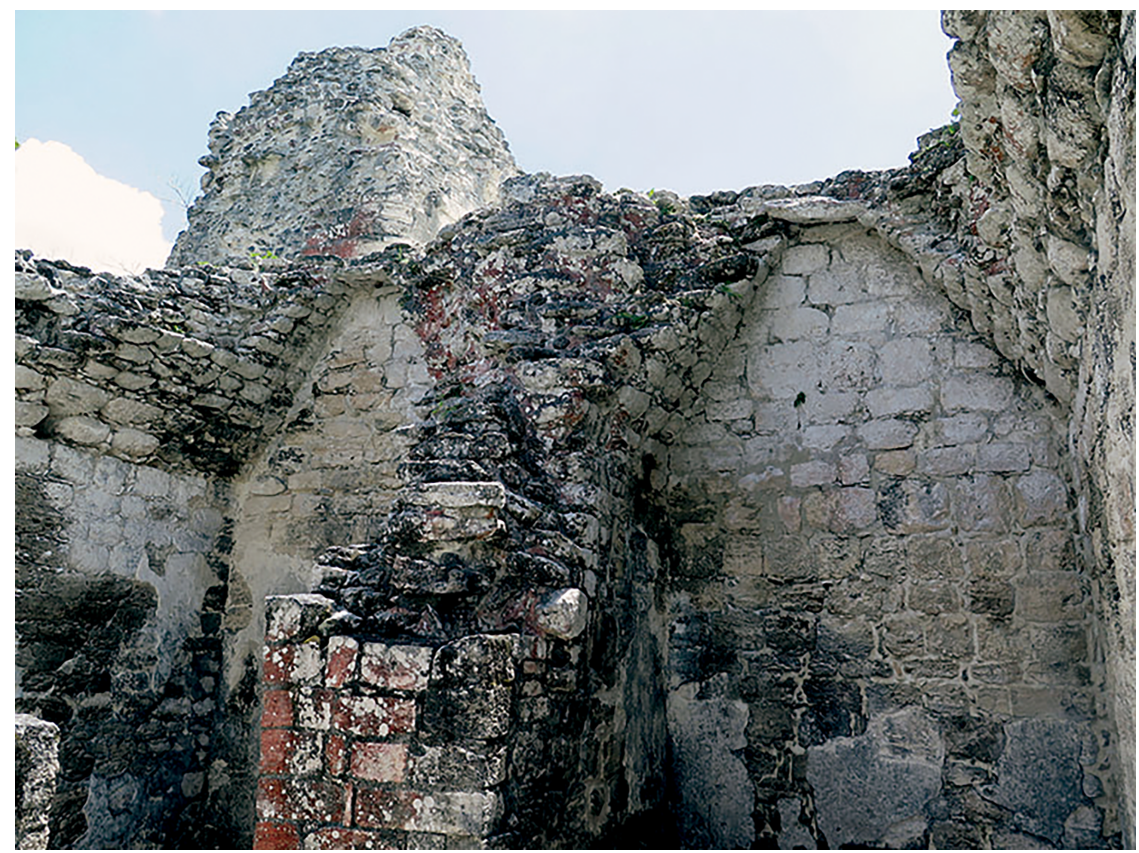

Figura 1. Estructura I de Chicanná (Fotografía de Laura Gilabert).

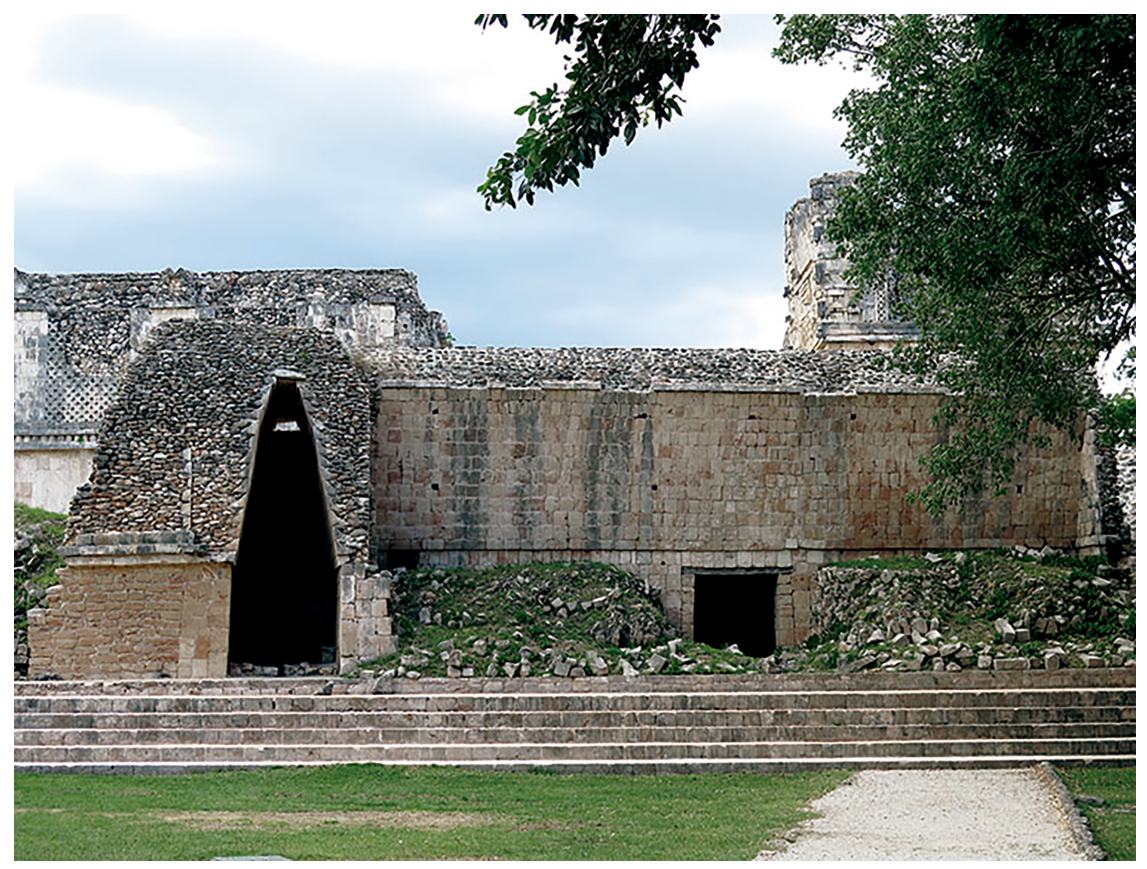

Figura 2. Edificio 22 de Uxmal (Fotografía de Laura Gilabert). 
Uno de los aspectos más importantes a tener en cuenta al momento de analizar las diferentes variantes de la bóveda y su evolución temporal es la forma de las dovelas. Como veremos a continuación, en función de la zona geográfica y de la cronología del edificio, las dovelas presentan diferentes formas, tamaños, grados de labra y niveles de especialización.

\section{Objetivos y metodología}

El objetivo del presente estudio es proponer una clasificación de los tipos de dovelas de las bóvedas mayas, siendo este aspecto constructivo determinante para analizar la evolución temporal y las diferentes variantes geográficas de la bóveda en la arquitectura maya.

Este trabajo se enmarca en una investigación más amplia en la que se ha abordado el estudio de la bóveda maya desde el punto de vista arquitectónico, teniendo en cuenta los aspectos formales, geométricos, funcionales, constructivos, estructurales y simbólicos (Gilabert, 2018). Para ello, se realizó un amplio trabajo de campo que permitió registrar las características de una muestra de 391 bóvedas de diferentes zonas geográficas y períodos cronológicos. Para poder gestionar toda la información obtenida in situ, complementada con la de las fuentes bibliográficas, se diseñó una base de datos de bóvedas mayas que permite registrar todas sus características. A partir del análisis comparativo de este corpus, se ha propuesto como resultado una clasificación de las bóvedas mayas según diferentes criterios, y se han estudiado sus rasgos característicos y su evolución temporal en las principales zonas geográficas de las tierras bajas mayas.

Durante el trabajo de campo, organizado en varias campañas de toma de datos, se recopiló información sobre las características formales, geométricas y constructivas de las bóvedas, así como de su estado actual de conservación. En cuanto a la estereotomía, se recogieron datos sobre el tamaño y la forma de las dovelas de 311 bóvedas, pertenecientes a 47 sitios arqueológicos de las zonas de Petén, la cuenca del río Usumacinta, las áreas Río Bec, Chenes y Puuc, así como la zona norte de Yucatán.

El estudio formal y geométrico de las dovelas ha sido posible en muchos casos debido a la situación de derrumbe parcial en la que se encuentran numerosos edificios abovedados. Resulta frecuente encontrar que, tras el colapso de los dinteles de las puertas, las partes de las bóvedas que apoyan sobre éstos se han desplomado, dejando a la vista una sección constructiva de las mismas que permite analizar sus características estereotómicas.

A partir de los datos obtenidos se han establecido siete tipos de dovelas, que se describen a continuación. La introducción de toda la información recopilada en una base de datos de tipo relacional ${ }^{2}$ nos ha permitido comparar las caracte-

\footnotetext{
${ }^{2}$ La base de datos está estructurada en tres tablas de datos relacionados entre sí: la tabla "si-
} 
rísticas formales y constructivas de las bóvedas y cruzar los datos de diferentes zonas geográficas y períodos cronológicos. De esta manera hemos podido comprobar qué formas de bóvedas puede generar cada tipo de dovela, analizar en qué áreas geográficas se dan los tipos propuestos y observar la evolución temporal de las bóvedas en cada región a partir de la información cronológica de los edificios a las que pertenecen.

\section{Tipos de dovelas de las bóvedas mayas}

Los criterios para clasificar los diferentes tipos de dovelas han sido: el material utilizado, la forma de la pieza y la calidad de la talla. La utilización de un tipo u otro de dovela depende de factores geográficos, temporales y estilísticos del edificio, y determina en muchos casos variables como la forma de la bóveda, el aparejo de la fábrica, la regularidad del intradós obtenida y los detalles constructivos en el arranque inferior y en el remate superior de las bóvedas.

A continuación, se describen los tipos de dovela propuestos, empezando por los que presentan un nivel de labra menor y siguiendo por los que requieren un mayor trabajo de talla y tienen un mayor grado de especialización. ${ }^{3}$ Los tipos propuestos se dividen en dovelas trabajadas y no trabajadas. En las dovelas trabajadas se incluye un tercer grupo de dovelas especializadas (Figura 3).

\section{A. Dovelas no trabajadas}

Al primer grupo pertenecen las dovelas que no requieren trabajo de labra. Su forma y tamaño dependen del tipo de piedra y la metodología de extracción. Se clasifican en dos tipos:

Dovelas sin labra

El primer tipo son las dovelas de las bóvedas que se construyen con piedras toscas sin labrar, dispuestas en voladizo una sobre otra. Para ir acomodándolas durante la ejecución se calzan con ripios o piedras menores, y resulta una superficie del intradós muy irregular que era cubierta con una gruesa capa de mortero

tio", la tabla "edificio" y la tabla "bóveda". De esta forma, se pueden comparar características de las bóvedas según variables que se refieren al edificio al que pertenecen, como la datación cronológica o la tipología arquitectónica. La tabla "sitio" permite introducir la variable "zona geográfica", para comparar las características de las bóvedas por regiones o áreas estilísticas.

${ }^{3}$ Un caso muy especial, que no procede considerar en esta clasificación, son las bóvedas del sitio de Comalcalco, construidas con ladrillo. Debido presumiblemente a la escasez de piedra en la zona, en este sitio se erigieron, en las épocas más tempranas, estructuras de tierra compactada revestidas de cal o ladrillo y, posteriormente, muros y bóvedas de fábrica completa de ladrillo (Andrews, 1989). Se trata de un caso aislado en el área maya, pero vale la pena señalarlo y observar que, aunque se empleara un material distinto, los mayas utilizaron la misma técnica de bóvedas por aproximación de hiladas. 


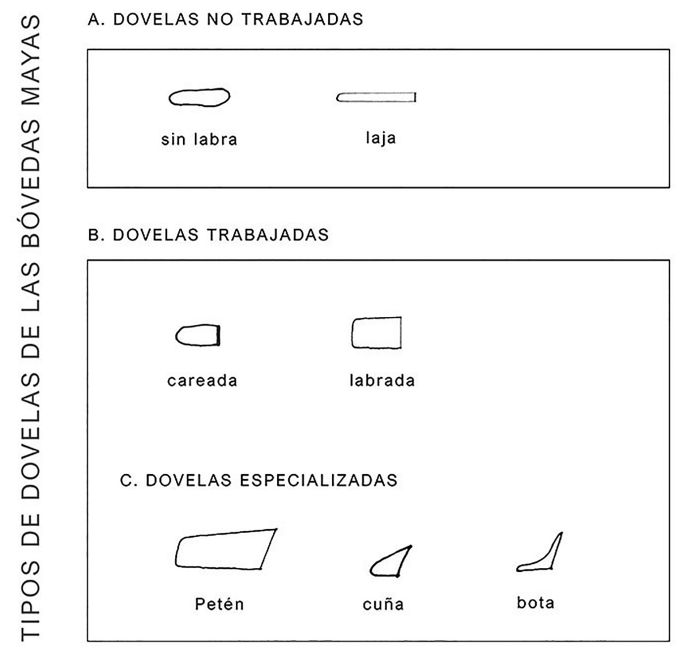

Figura 3. Tipos de dovelas de las bóvedas mayas (L. Gilabert).

de regularización de varios centímetros de espesor, sobre la cual se aplicaba el revestimiento de estuco final.

Según el tipo de piedra disponible, las dovelas sin labra son a veces mampuestos con formas más o menos redondeadas y otras veces son losas planas alargadas de gran tamaño. El plano de apoyo de unas dovelas sobre otras no es siempre horizontal, en muchos casos se disponen inclinadas como fruto del resultado del proceso constructivo (Figura 4).

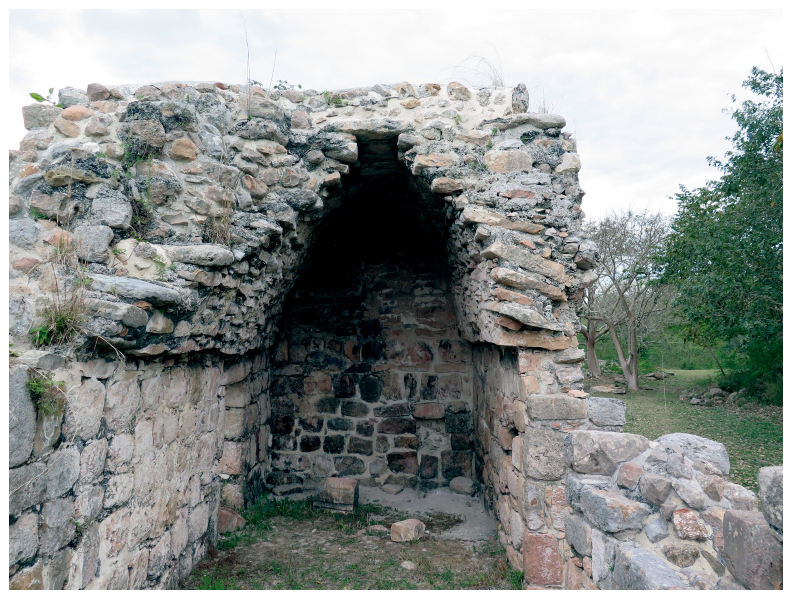

Figura 4. Bóveda del Edificio CA-6 en el Grupo Ah Canul de Oxkintok (Fotografía de Laura Gilabert). 
Como veremos más adelante, existen bóvedas con dovelas sin labra en prácticamente todas las zonas geográficas, muchas veces pertenecen a edificios de épocas tempranas, pero no en todos los casos. En el área de Río Bec, por ejemplo, en sitios como Becán o Chicanná, las bóvedas se construyen, por lo general, con piedras poco trabajadas.

Dovelas de laja

El tipo de dovela denominado "laja" se da solamente en sitios de la cuenca del río Usumacinta, como Piedras Negras, Yaxchilán o Palenque (Figura 5). Según varios estudios, esta área es geológicamente distinta al resto de las tierras bajas, pues se compone principalmente de sedimentos no calcáreos (Smith, 1962: 206). Es probable que este hecho posibilitara la extracción de la piedra en lajas o formas muy planas con superficies horizontales y de poco espesor. En cuanto al grado de talla, este tipo de dovelas se puede considerar también como no trabajado, pero sus proporciones y su forma permiten diferenciarlo claramente del tipo anterior. La construcción de las bóvedas con lajas se realizaba con planos de apoyo horizontales y, según la regularidad de sus caras, se intercalaban ripios para ir acomodando las dovelas.

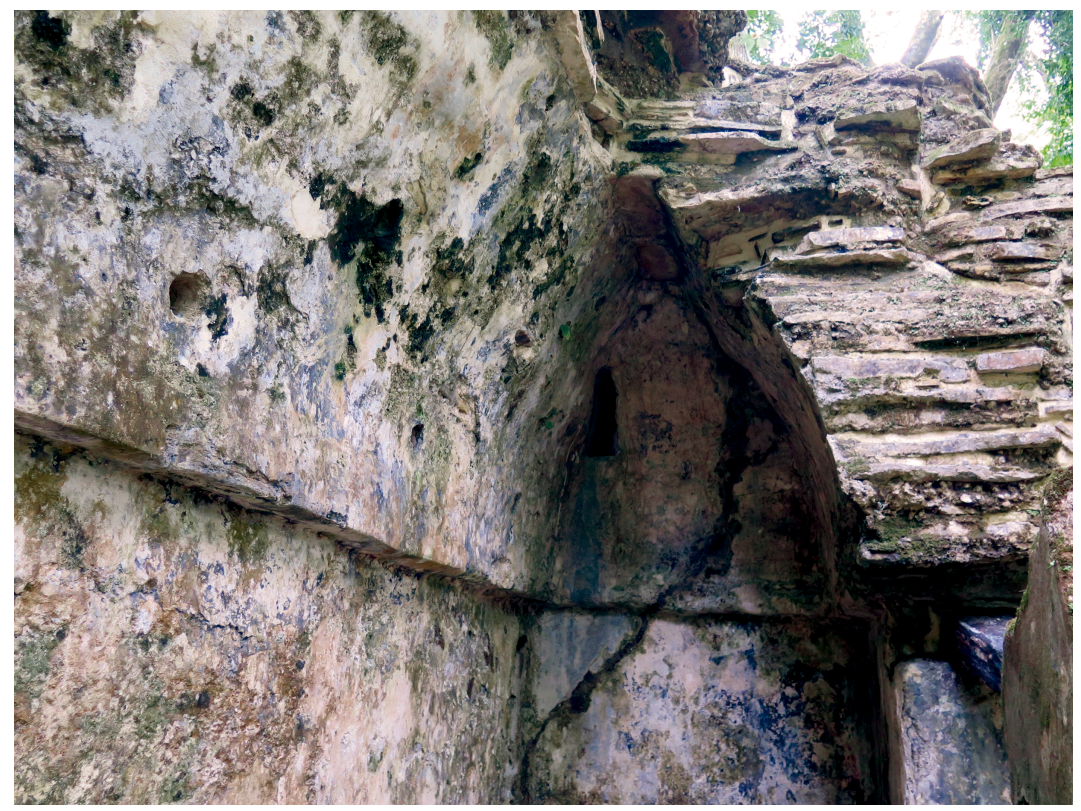

Figura 5. Bóveda del Edificio 7 de Yaxchilán (Fotografía de Laura Gilabert).

Por lo general, en los edificios de esta región se utilizaron sillares de mayor espesor para los muros y lajas para las bóvedas, lo que les debió permitir tener un mayor grado de control sobre la forma de la sección de la bóveda resultante. 
Así, obtuvieron formas escalonadas, de botella o perfectamente rectas, como en el caso de la arquitectura de Palenque. En dicho sitio las bóvedas se construyeron con lajas muy planas y largas, que no necesitaban piedras intermedias, y cuya longitud genera una gran cohesión en el espesor de la bóveda. La utilización de dovelas de laja está íntimamente relacionada con algunas de las soluciones propias y características de la arquitectura del Clásico Tardío de Palenque, por ejemplo, los nichos de formas lobuladas que aligeran las bóvedas (Figura 6). La cohesión interior de la fábrica, generada por la construcción de todo su espesor con lajas horizontales, hacía posible asimismo la gran inclinación de los frisos de las fachadas y ha influido en la forma de colapso de las bóvedas, pues ha permitido que, en muchos casos, tras el derrumbe de los dinteles de las puertas, se formen arcos de descarga muy rebajados y el lado exterior de la bóveda pueda mantenerse prácticamente íntegro.

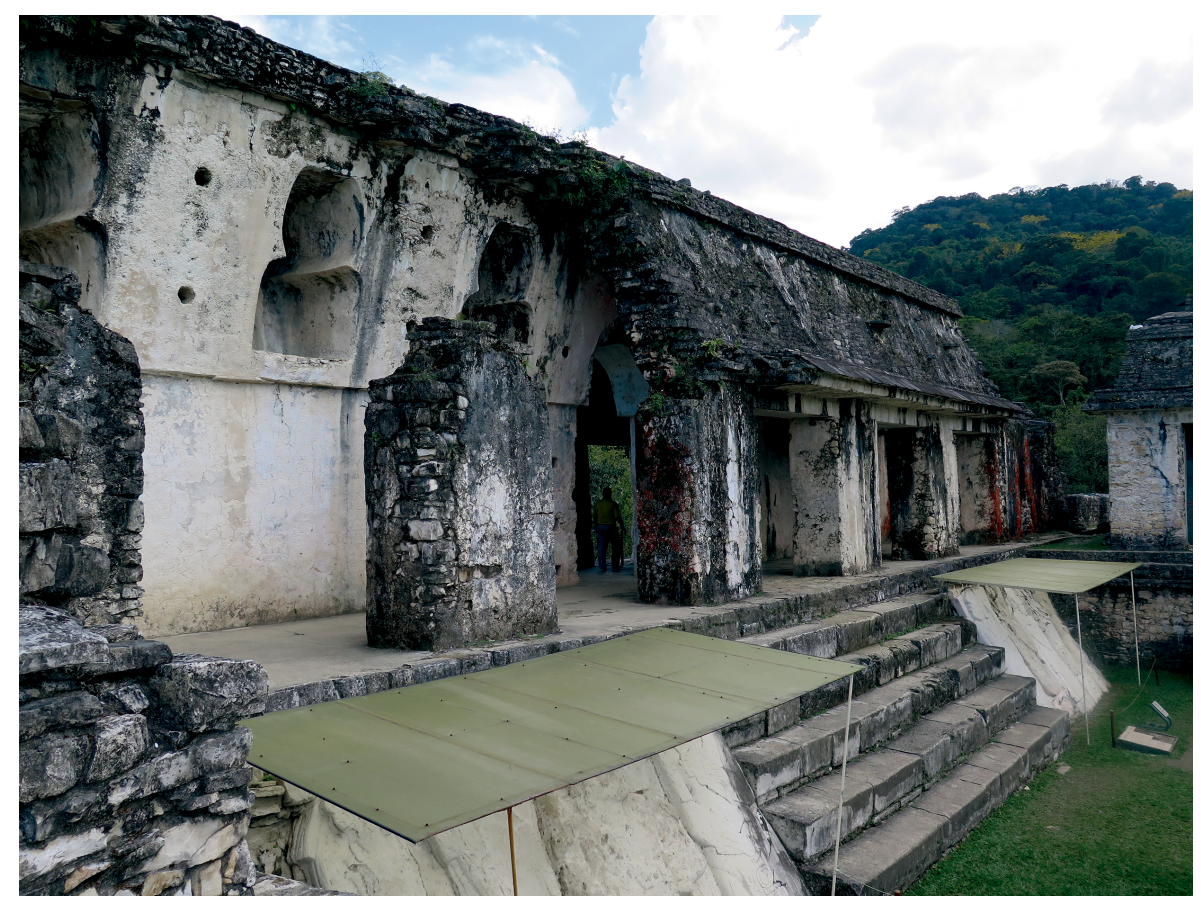

Figura 6. Casa A del Palacio de Palenque (Fotografía de Laura Gilabert).

\section{B. Dovelas trabajadas}

Los tipos de dovelas que se abordan a continuación requieren, en mayor o menor grado, ser labradas de una forma determinada, lo que implica la elección previa de una forma de la sección de la bóveda. En función del número de caras labradas se distingue entre dovelas careadas y dovelas labradas: 
Dovelas careadas

Las dovelas trabajadas de forma más sencilla serían las careadas, es decir, mampuestos a los que se les talla una sola cara para obtener una superficie plana. Con dovelas careadas se construían en ocasiones bóvedas de sección escalonada, como las de la Estructura E-X de Uaxactún (Figura 7). También existen casos de bóvedas de dovelas careadas con formas rectas, por ejemplo, las de la Estructura I de Chicanná, con una cara labrada ya con la inclinación aproximada del intradós (ver Figura 1).

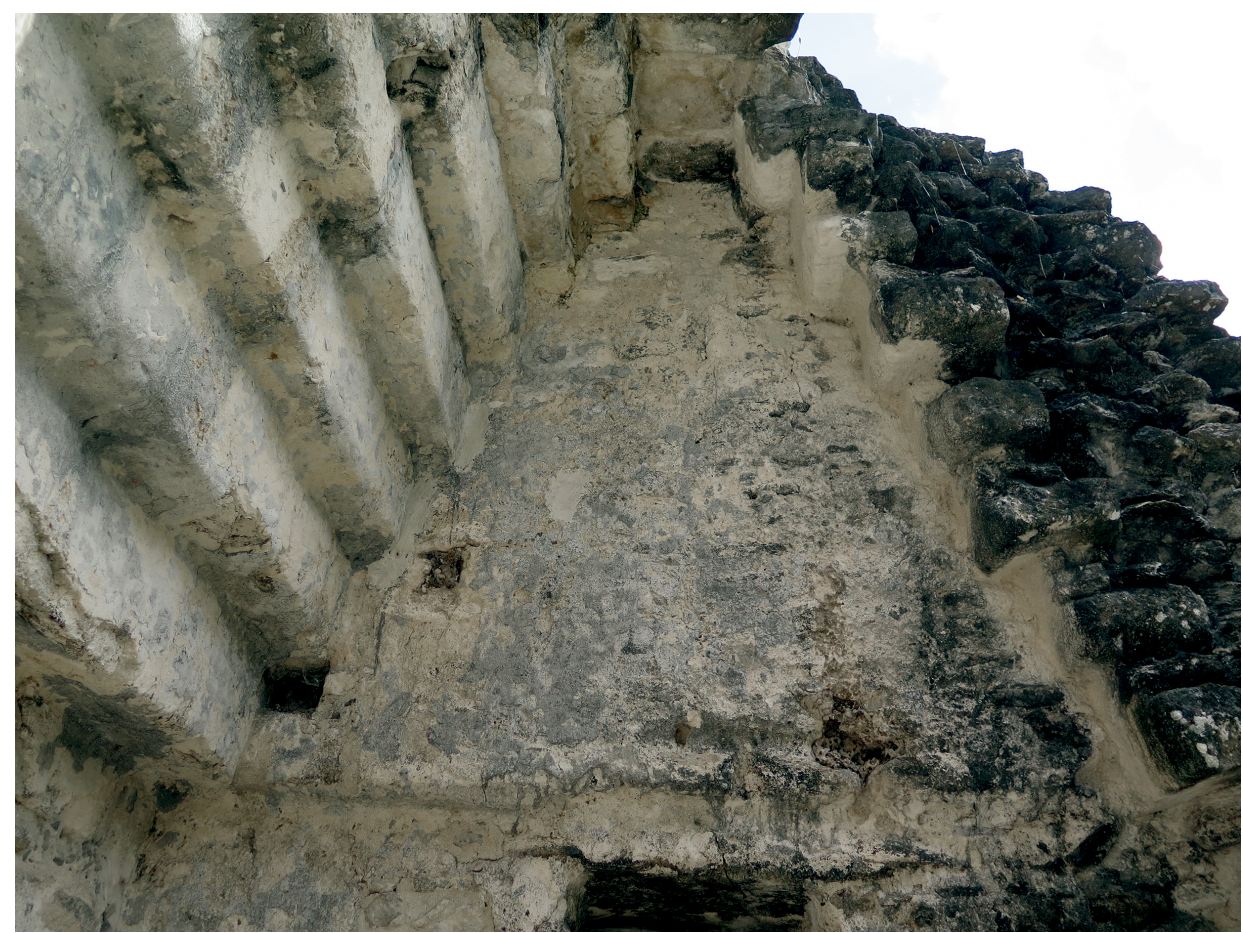

Figura 7. Bóveda de la Estructura E-X de Uaxactún

(Fotografía de Laura Gilabert).

Dovelas labradas

En esta tipología de dovela está labrada más de una cara: al menos la exterior que forma el intradós, con un corte vertical o inclinado, y las dos caras, superior e inferior, que permiten el apoyo horizontal de cada dovela sobre la anterior. En ocasiones están labradas cinco de sus caras, por ejemplo en las bóvedas escalonadas del Juego de Pelota de Copán (Figura 8). Dependiendo de la homogeneidad del tamaño de las dovelas, se pueden colocar en hiladas horizontales regulares y, según la calidad de la talla y la planitud de las superficies obtenidas, se intercalan ripios para ir acomodando las dovelas. 


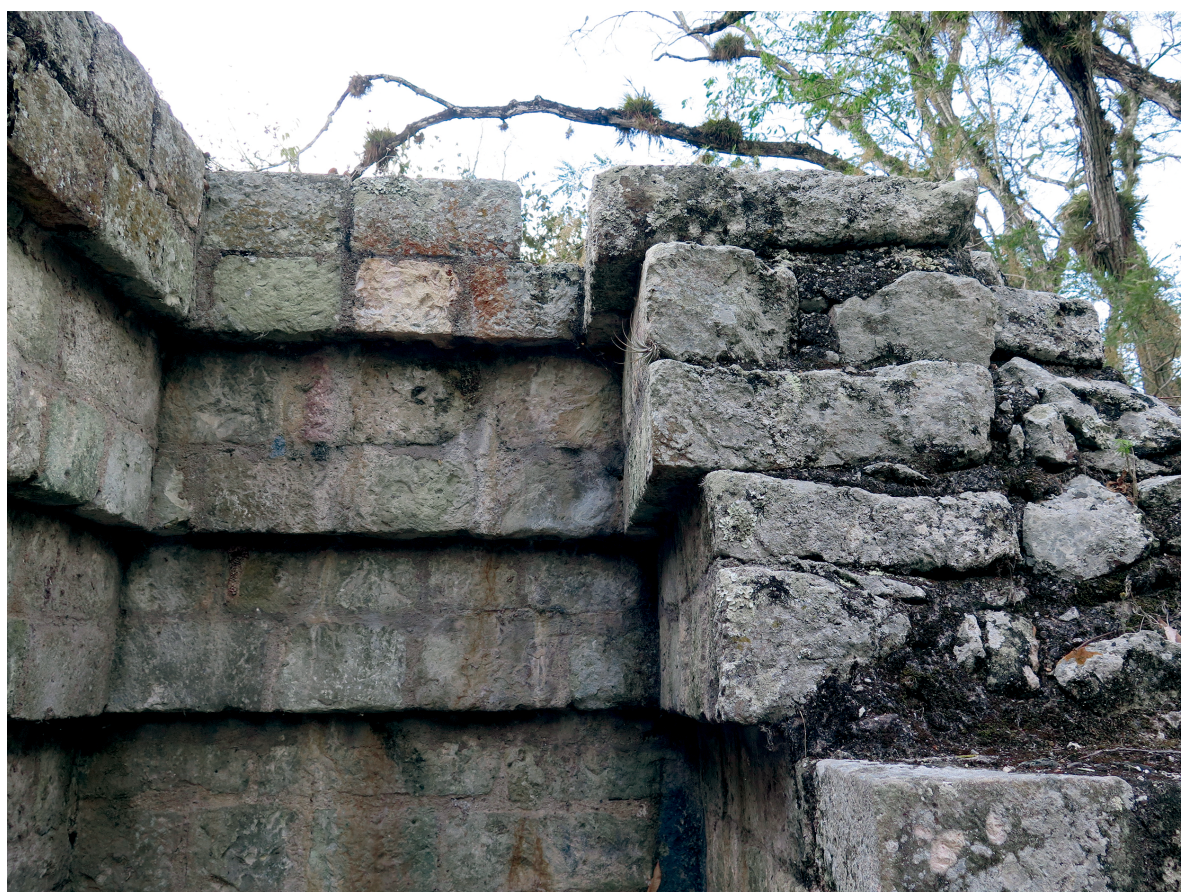

Figura 8. Bóveda en el edificio oriente del Juego de Pelota de Copán (Fotografía de Laura Gilabert).

\section{Dovelas especializadas}

Los siguientes tipos de dovelas son piezas especializadas, es decir, están talladas con una forma específica para su función y, por tanto, pertenecen a un desarrollo más avanzado de la técnica que requiere un mayor dominio de la estereotomía. Las dovelas altamente especializadas aparecen en bóvedas de zonas geográficas y períodos temporales concretos en los que la técnica estereotómica alcanzó su máximo auge.

\section{Dovelas Petén}

Las dovelas denominadas "Petén" están talladas con una forma específica para su función e implican el diseño previo de la forma de la bóveda. Su nombre se debe a que son muy características de la arquitectura más avanzada del área del Petén, y exclusivas de esta zona geográfica.

Tales dovelas son grandes piezas bien labradas, con una de sus caras preparada con la inclinación del intradós de la bóveda y las otras cuatro caras paralelas dos a dos para disponer una dovela sobre otra en hiladas horizontales. Por lo general, con estas dovelas no era necesario intercalar ripios, pues las caras inferior 
y superior eran planos horizontales que permitían un adecuado acoplamiento entre las hiladas de altura regular. Sólo en algunos casos más primitivos se intercalaron pequeñas lascas para absorber las irregularidades. La parte posterior suele ser redondeada y a veces está desbastada para asegurar una correcta traba entre la hoja exterior de dovelas y el relleno interior de mampostería y argamasa. El tamaño de las dovelas Petén varía, pero los valores más comunes están entre 25 y $35 \mathrm{~cm}$ de base, entre 30 y $40 \mathrm{~cm}$ de altura en la cara exterior y la profundidad oscila entre los 30 y $60 \mathrm{~cm}$ en la mayoría de los casos. Por lo general, este tipo de dovela ofrecía una superficie del intradós uniforme y bastante regular y sólo era necesaria una capa de estuco de revestimiento (Figura 9).

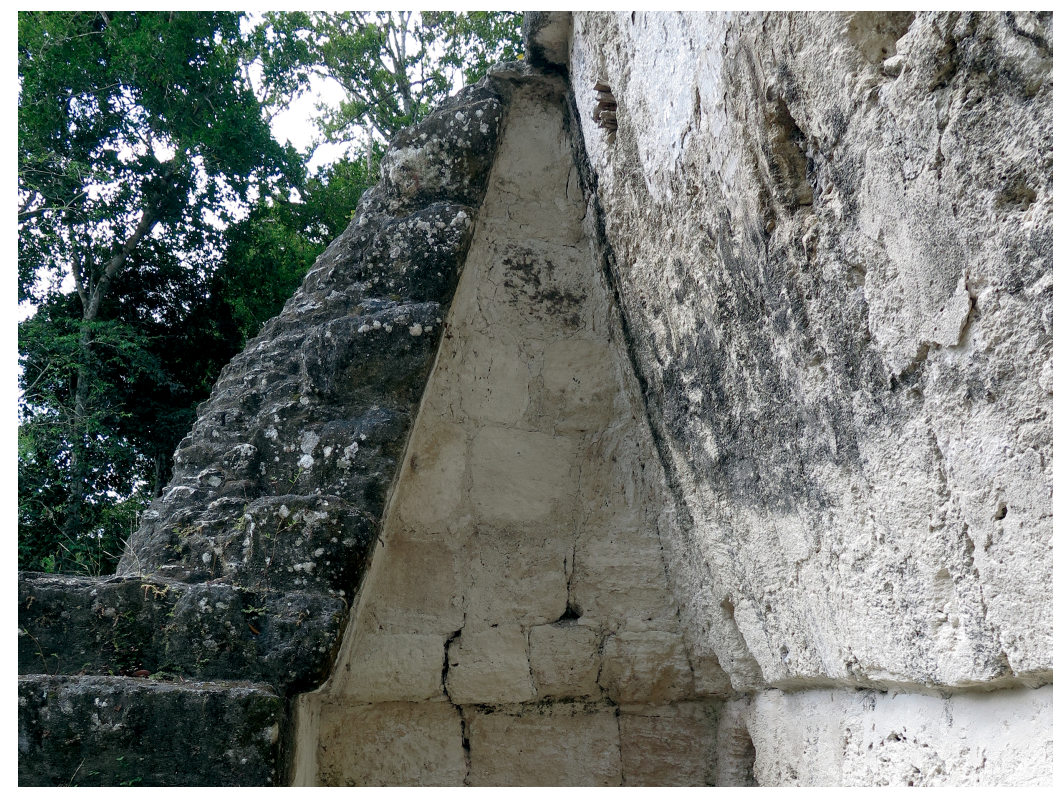

Figura 9. Bóveda con dovelas Petén en el Edificio D de Nakum (Fotografía de Laura Gilabert).

Normalmente las dovelas Petén se utilizan en bóvedas de sección recta con una geometría que ha sido previamente definida. Los constructores planificarían la pendiente de la bóveda a partir de la luz y la altura de la estancia y usarían reglas empíricas para establecer los valores máximos de las inclinaciones, de modo que se asegurara el equilibrio estático de la estructura. Parece lógico pensar que dispondrían de un sistema para medir las pendientes y trasladarlas a los bloques de piedra extraídos de las canteras. ${ }^{4}$

\footnotetext{
${ }^{4}$ No hay evidencia en el área maya de trazado de monteas, pero los constructores definían previamente la geometría de las bóvedas y seguramente utilizarían algún sistema de plantillas o guías para tallar este tipo de dovelas con la inclinación del intradós de la bóveda.
} 
En algunos edificios se construyeron bóvedas escalonadas con este tipo de dovelas, disponiendo cada hilada o cada dos hiladas con un ligero voladizo sobre la anterior, de manera que resultan escalonamientos que alternan planos inclinados y planos horizontales. Algunos ejemplos de ello se encuentran en el Palacio de las Ventanas (Figura 10) y el Edificio 5D-91 de Tikal, o el Edificio Rde Nakum.

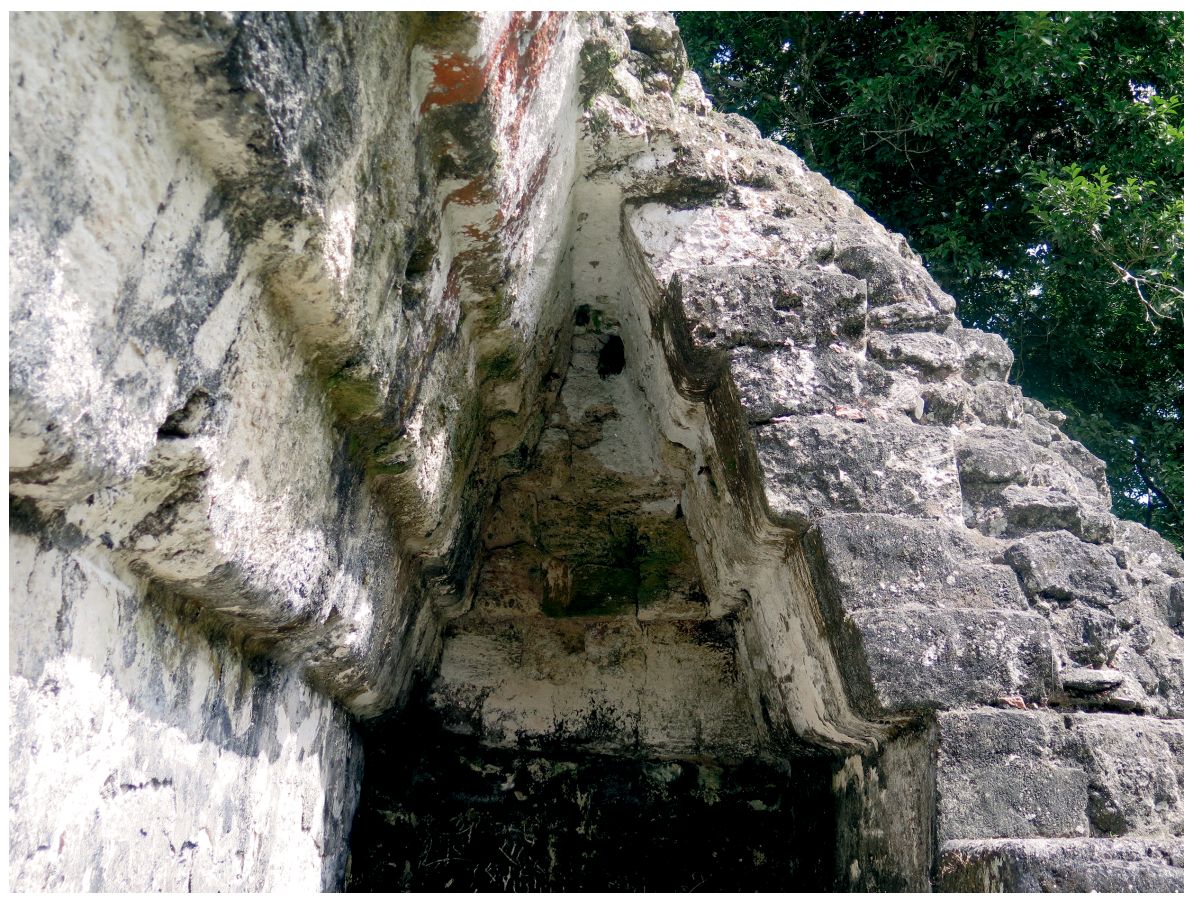

Figura 10. Bóveda escalonada con dovelas Petén en el Palacio de las Ventanas de Tikal (Fotografía de Laura Gilabert).

Dovelas cuña

Las dovelas denominadas "cuñas" se dan en bóvedas de edificios de las áreas Puuc y Chenes. Tienen una cara rectangular bien labrada que se coloca hacia el interior de la estancia y en la parte posterior adoptan formas con secciones redondeadas, triangulares, o a veces con una larga espiga para trabarse con el núcleo de mampostería y argamasa. Las dovelas de este tipo, sobre todo las más perfeccionadas, no tienen superficies horizontales para ir apoyando las hiladas progresivamente, sino que sólo se tocan en los bordes. La calidad de la talla y la perfección son variables: en los casos más toscos se intercalan pequeñas lascas para absorber irregularidades, pero en general la superficie interior resultante suele ser bastante uniforme y lisa (Figura 11). Las cuñas eran piezas relativamente estandarizadas, de lo que se puede deducir una posible sistematización del trabajo de cantería (Andrews, 1995: 126). 


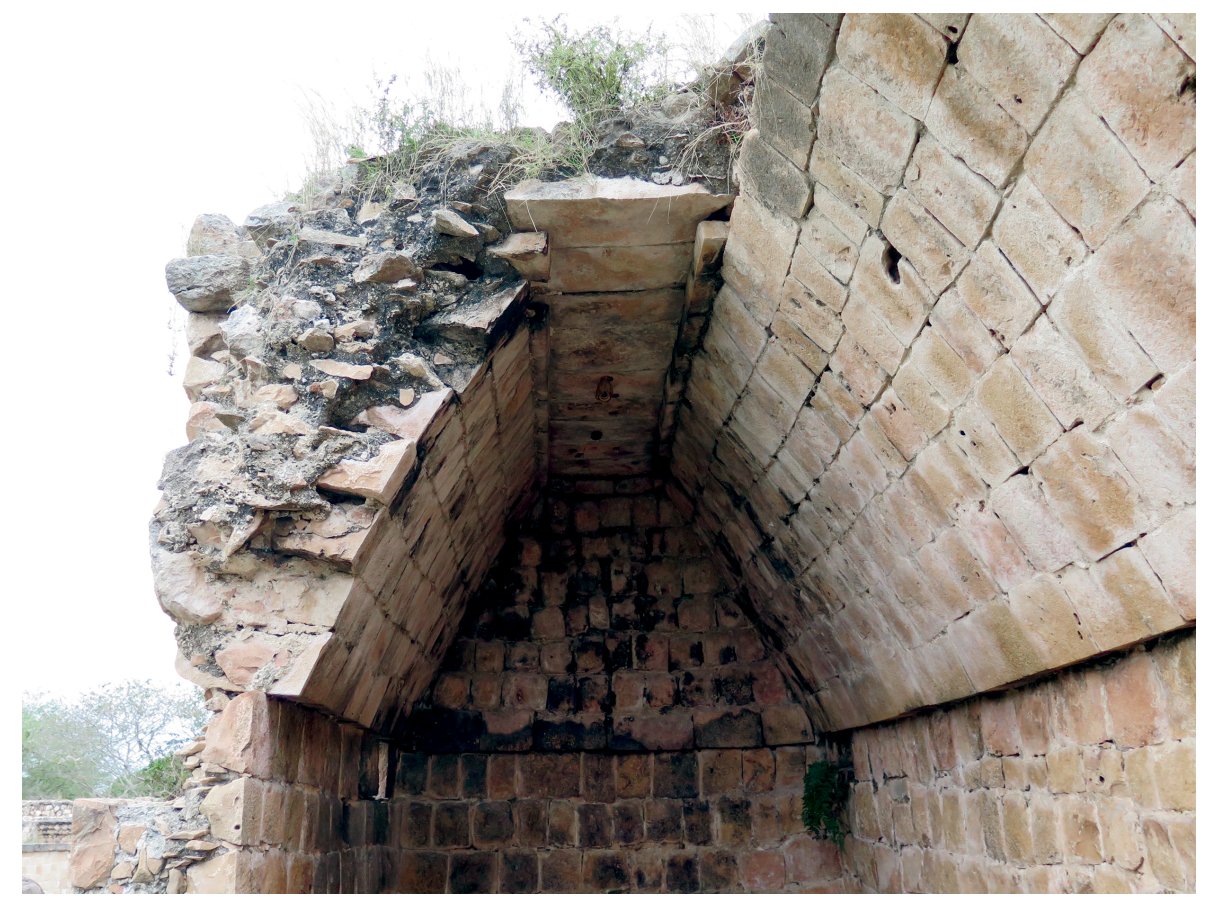

Figura 11. Bóveda del Palacio Chich o CA-7 de Oxkintok (Fotografía de Laura Gilabert).

En la arquitectura Puuc, la gran mayoría de las bóvedas con este tipo de dovelas se rematan con una moldura previa a la tapa. Tal detalle constructivo podría ser consecuencia de la propia estereotomía de las dovelas: al minimizarse la superficie de apoyo de una dovela sobre la siguiente, se coloca una pieza plana sobre la última dovela para obtener un plano de apoyo uniforme para las piezas de tapa (ver Figura 11). Otro detalle constructivo característico de las bóvedas Puuc con dovelas cuña es el del arranque: sobre la coronación del muro se sitúa una hilada de grandes piedras horizontales que garantizan el apoyo y, a continuación, se van colocando las dovelas y el relleno posterior. Como resultado, en el intradós se genera una primera hilada diferenciada por su proporción, lo que es un rasgo característico de las bóvedas de esta región, desde el Puuc Temprano y durante todo el Puuc Clásico, y que en muchos casos se aplica también a los muros testeros (ver Figura 11).

\section{Dovelas bota}

En la región Puuc la tecnología constructiva de las bóvedas se fue sofisticando progresivamente hasta llegar a las dovelas altamente especializadas y conocidas como "botas". En estas piezas con sección en forma de "L", la cara destinada al intradós de la bóveda es rectangular y está perfectamente labrada, y en la parte 
trasera inferior tiene una base para anclarse al relleno y recibir la carga vertical que la equilibra. Dichas dovelas suelen tener una de las caras labrada con la inclinación del intradós de la bóveda y otra horizontal como plano de apoyo, lo que permitiría ejecutar la bóveda por tongadas horizontales ${ }^{5}$ (Figura 12).

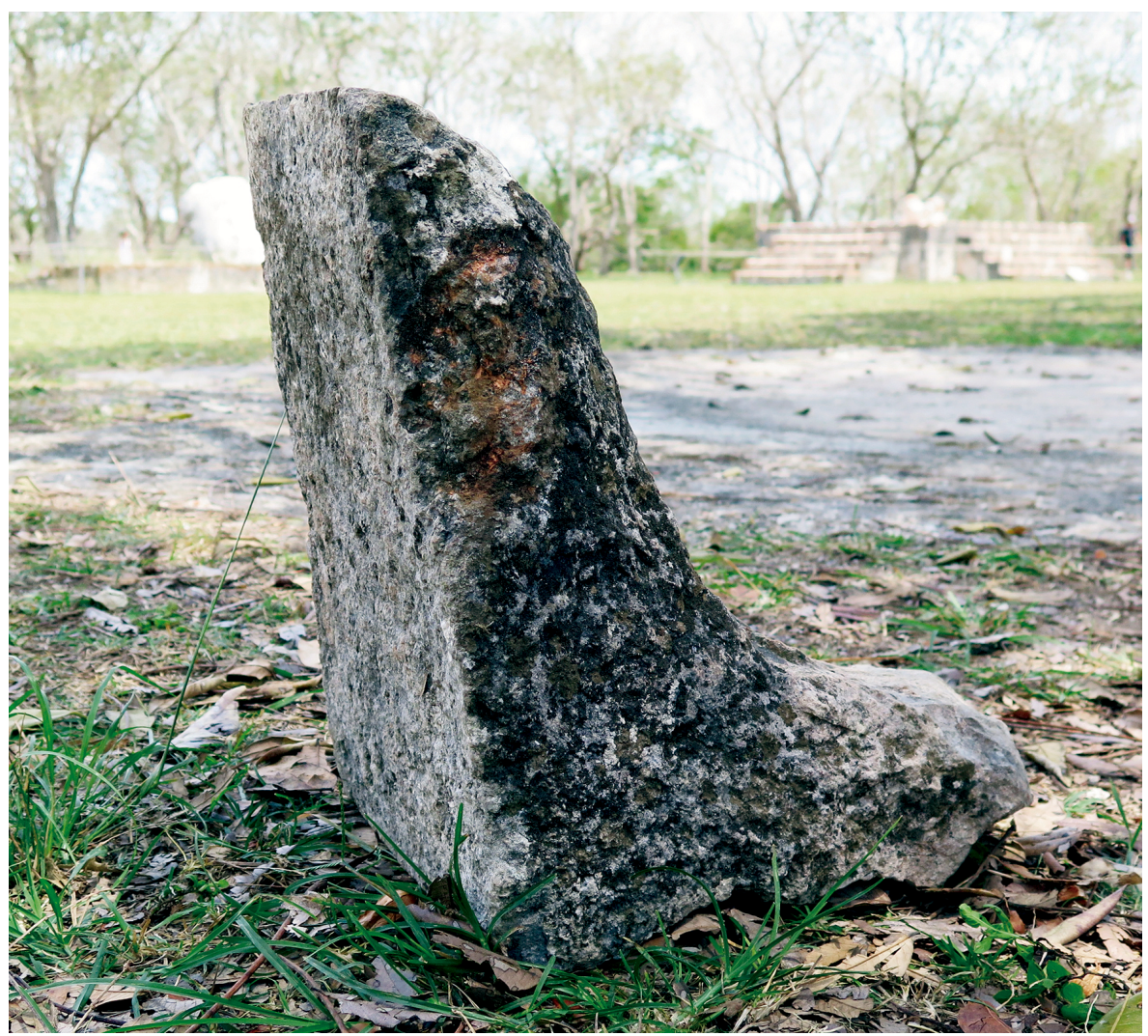

Figura 12. Dovela en forma de bota en el entorno del Palacio del Gobernador de Uxmal (Fotografía de Laura Gilabert).

Las bóvedas construidas con dovelas de bota tienen, por lo general, forma recta, y en algunos casos ligeramente cóncava. Se rematan con la moldura o ménsula superior y se inician con una hilada de arranque formada por grandes bloques planos de apoyo sobre el muro. La máxima calidad de labra de las dovelas de bota se alcanzó en el sitio de Uxmal, en edificios como la Casa de las Tortugas o el Palacio del Gobernador. En las bóvedas de estos edificios las dovelas

\footnotetext{
${ }^{5}$ En algunos casos se han identificado dovelas bota en las que el plano de apoyo no es horizontal, lo que implica una técnica diferente de puesta en obra. Un ejemplo de ello es la Estructura 1 de Chacmultún.
} 
se disponen en hiladas uniformes que se mantienen también en los testeros. Las juntas entre las diferentes piezas son líneas perfectamente rectas que se reducen al mínimo, y la superficie del intradós resultante es totalmente lisa, por lo que sólo requeriría una fina capa de estuco de revestimiento (Figura 13).

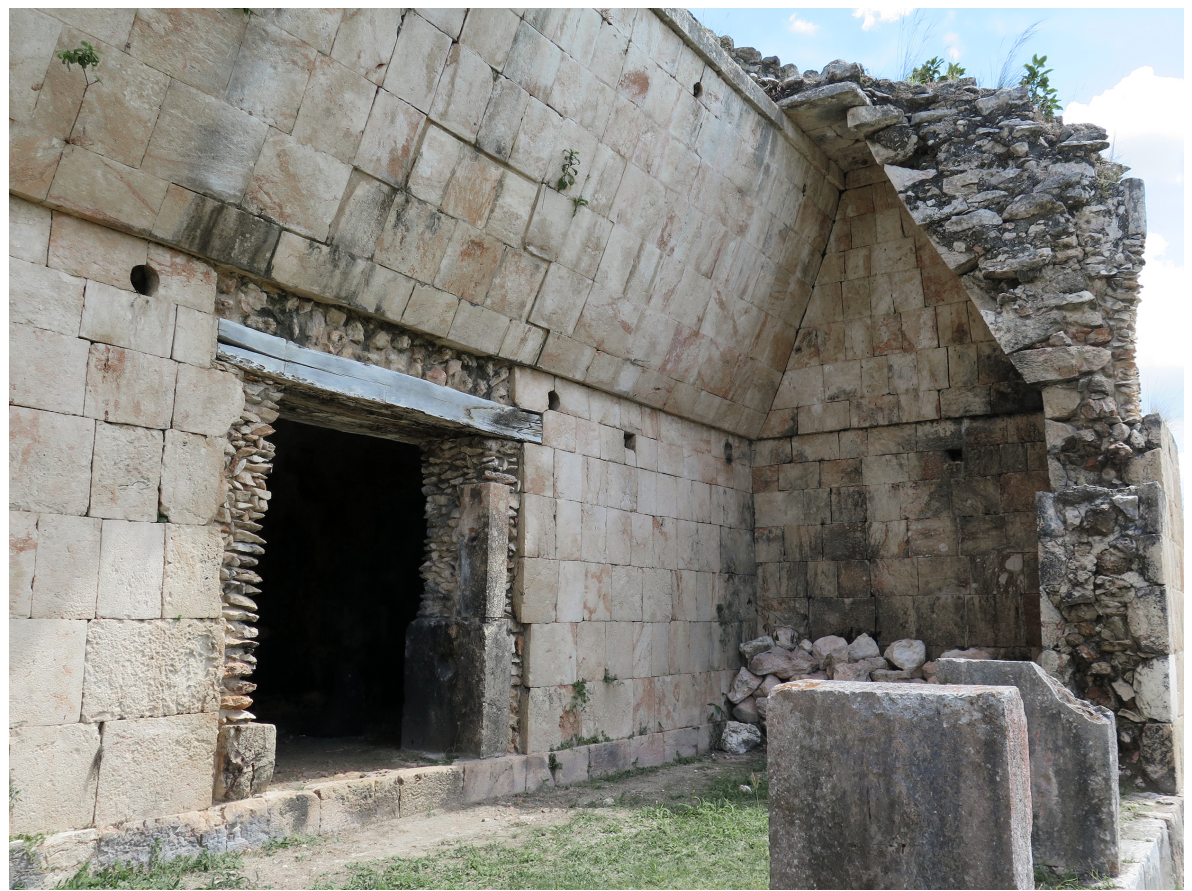

Figura 13. Bóveda del cuarto oeste de la Casa de las Tortugas de Uxmal (Fotografía de Laura Gilabert).

\section{Los tipos de dovelas en las diferentes zonas geográficas}

La construcción de una base de datos relacionados de bóvedas mayas nos ha permitido comparar sus diferentes variables y estudiarlas por áreas geográficas, períodos temporales o tipologías arquitectónicas. En cuanto a los tipos de dovelas, algunos de los resultados más interesantes se han obtenido analizando su utilización en las diferentes zonas geográficas de las tierras bajas mayas (Figura 14). Para ello, los sitios arqueológicos registrados se han asignado a las "provincias estilísticas" propuestas por Paul Gendrop (1983: 16-17), que divide las tierras bajas mayas del sur en las áreas de Petén y las cuencas de los ríos Usumacinta, Pasión y Motagua. En las tierras bajas mayas del norte, a las áreas delimitadas por Gendrop (Puuc, Chenes, Río Bec y Costa Caribe) se ha añadido la zona Norte de Yucatán, tal y como lo propone George Andrews (1995: 274). 


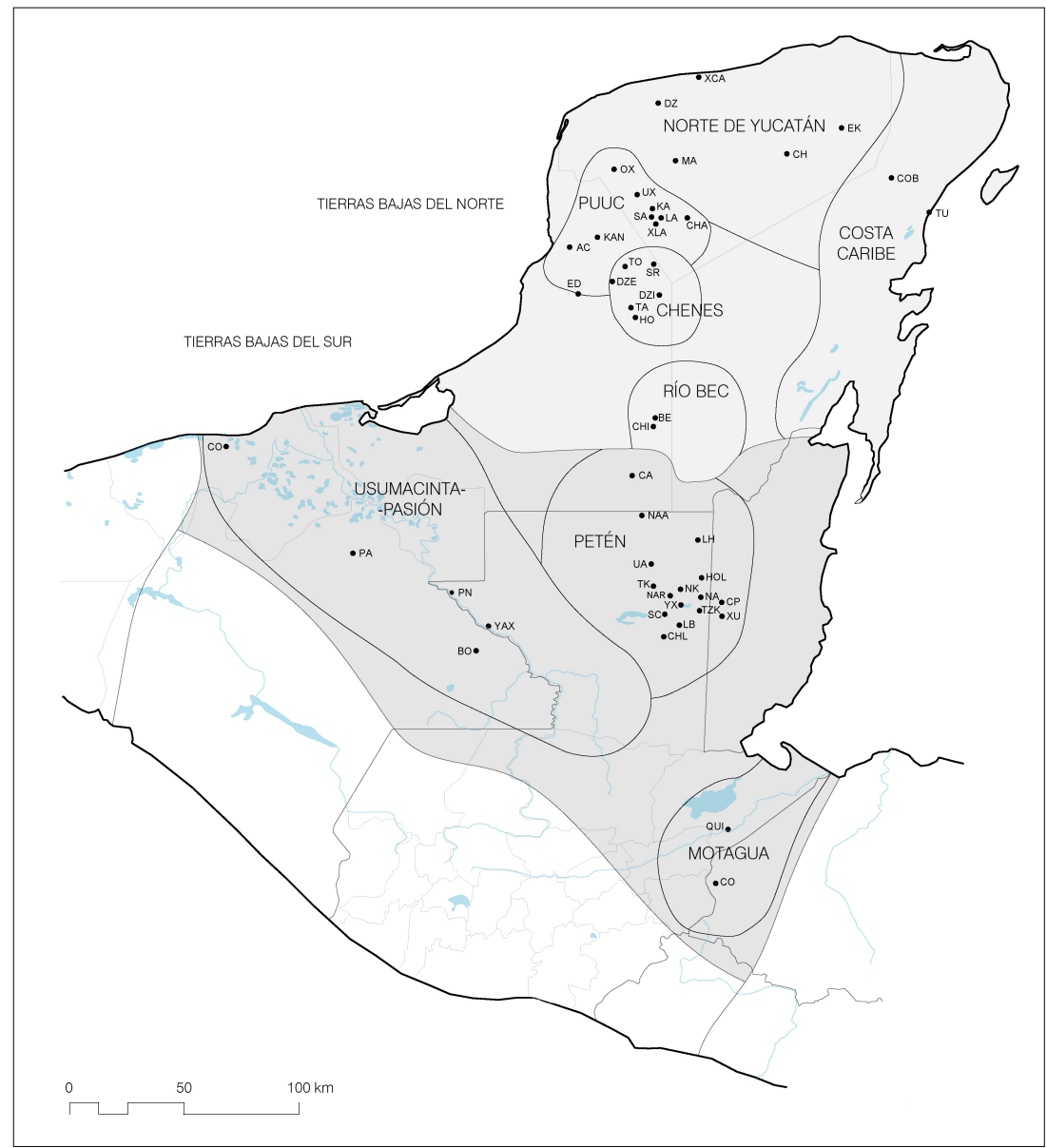

Figura 14. Mapa de las zonas geográficas de las tierras bajas mayas con las zonas consideradas (L. Gilabert).

La Figura 15 muestra los tipos de dovelas que aparecen en cada área geográfica. Vemos que las dovelas más especializadas sólo se utilizaron en una o dos regiones, tras un proceso evolutivo de la técnica estereotómica específico de cada zona. Tal es el caso de las dovelas Petén o las dovelas en forma de cuña y bota. El tipo de material pétreo puede determinar asimismo la utilización de una tipología determinada de dovela en una región, como ocurre con las dovelas de laja en el área del Usumacinta. Las dovelas sin labra, sin embargo, se utilizaron en todas las regiones, generalmente en las épocas más tempranas, y las dovelas con un nivel de trabajo intermedio, como las careadas o las labradas, se usaron en varias regiones y en diferentes períodos a medida que se avanzaba en la técnica constructiva. 


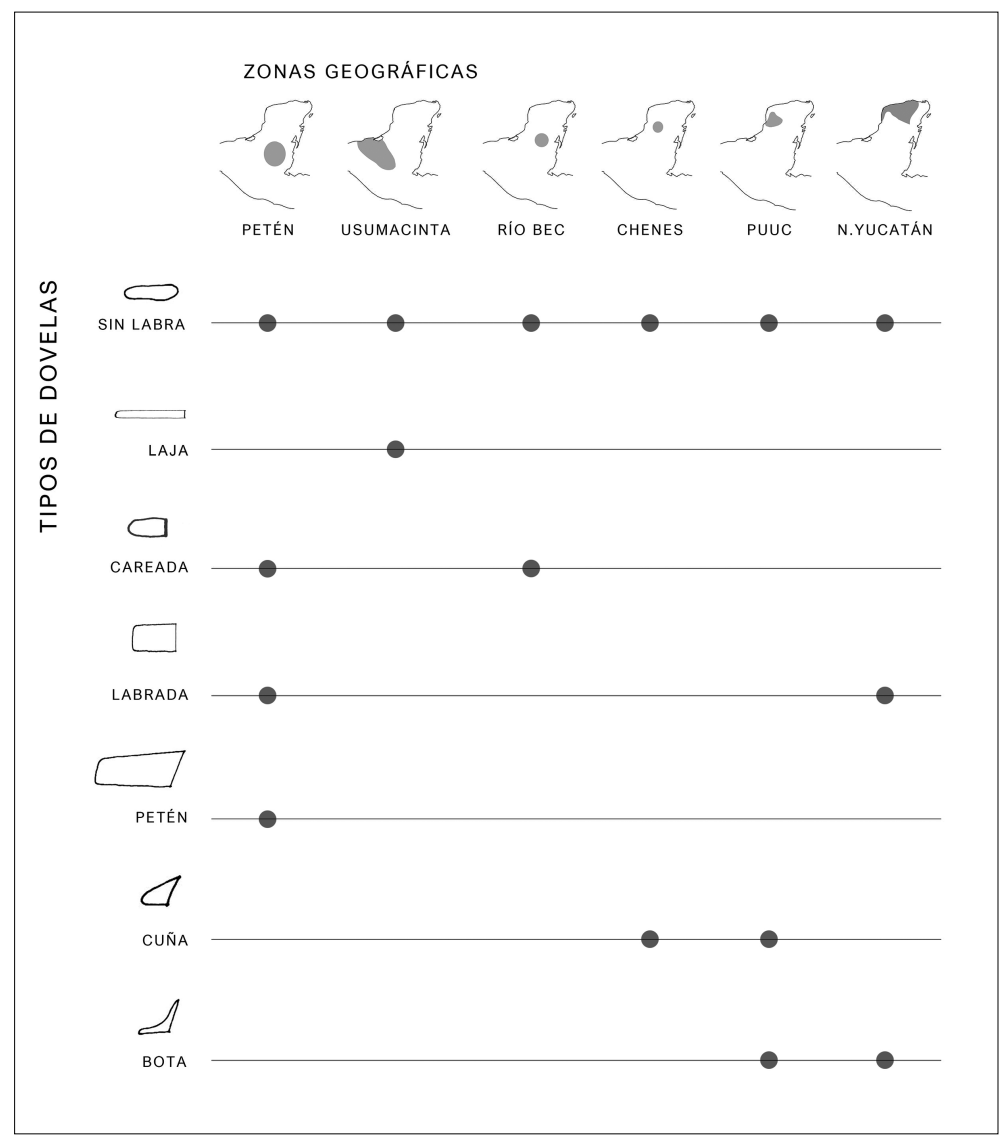

Figura 15. Tipos de dovelas registrados en cada una de las zonas geográficas estudiadas (L. Gilabert).

La utilización de un tipo concreto de dovela especializada en dos regiones vecinas puede indicar la existencia de relaciones y posibles transferencias de conocimiento constructivo. Un ejemplo de ello es la dovela cuña, que se da en las áreas Chenes y Puuc. La arquitectura Chenes se ha estudiado tradicionalmente junto a la de Río Bec por algunos rasgos arquitectónicos comunes, como las portadas zoomorfas. Sin embargo, si la analizamos desde el punto de vista de la tecnología constructiva de la bóveda, presenta más similitudes con la arquitectura de los estilos Puuc Temprano y Puuc Clásico, por ejemplo, en la utilización de dovelas talladas en forma de cuña o en el inicio del concepto de bóveda monolítica, formada por un relleno resistente y una "piel" exterior de piezas de piedra labrada (Figura 16). Esto muestra que muy probablemente hubo una transferencia de conocimiento constructivo entre estas dos áreas en una horquilla de tiempo determinada, lo que permite establecer hipótesis sobre las influencias en ambas direcciones. 


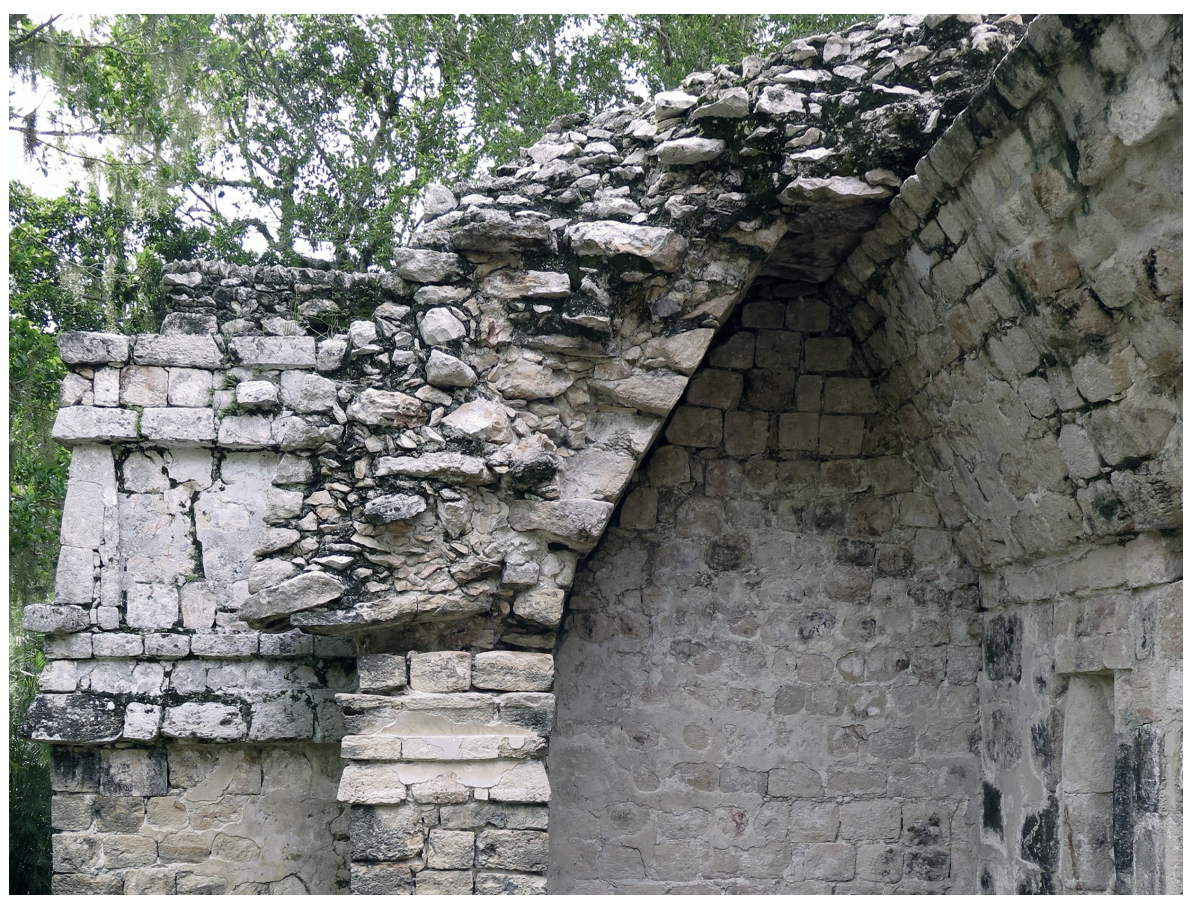

Figura 16. Bóveda del Palacio de Santa Rosa Xtampak (Fotografía de Laura Gilabert).

El sistema de bóvedas monolíticas se desarrolló con más énfasis en la arquitectura Puuc, donde el trabajo de cantería alcanza su máximo auge y nivel de especialización con las dovelas en forma de bota. Este tipo de dovela se transmite asimismo desde la arquitectura Puuc a determinados sitios del área norte de Yucatán como Chichén Itzá. En edificios del período conocido como Floreciente Modificado o "Tolteca" de este sitio, como el Templo de los Guerreros o el de los Tableros Esculpidos, se utilizó también la dovela bota, presumiblemente heredada de la arquitectura del estilo Uxmal Tardío.

\section{La influencia del tipo de dovela en la forma de las bóvedas}

La forma de la sección transversal de las bóvedas ha sido históricamente uno de los aspectos más utilizados para definir y clasificar las bóvedas mayas. Tradicionalmente se han representado, en gráficos comparativos, secciones de bóvedas rectas, cóncavas y escalonadas con otras formas más singulares. Sin embargo, analizar este factor formal de manera aislada ofrece una visión sesgada sobre la amplia variedad de soluciones de bóvedas que existen en el área maya, pues la 
forma de las bóvedas está íntimamente relacionada con aspectos constructivos como la estereotomía de las dovelas o el proceso constructivo del edificio. En la Figura 17 se relacionan los siete tipos de dovelas propuestos con las formas de sección transversal de la bóveda que generan, según los datos obtenidos in situ.

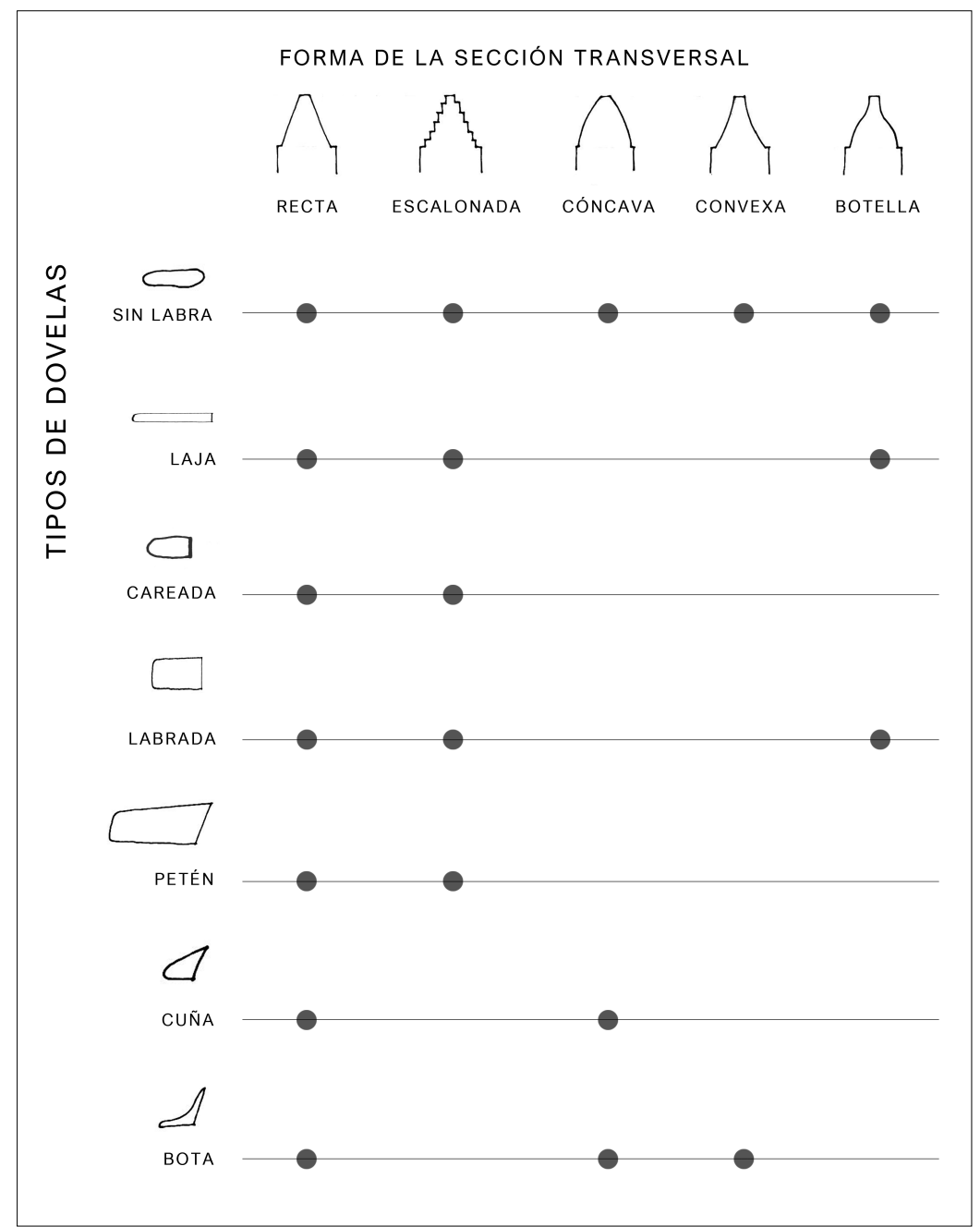

Figura 17. Formas de las bóvedas según el tipo de dovela utilizado (L. Gilabert).

Podemos ver que las dovelas sin labra generan bóvedas con todas las tipologías formales de la sección transversal: escalonadas, rectas, cóncavas, convexas y de botella, a tenor de cómo se vayan apoyando progresivamente los mampuestos. Con este tipo de dovela se solía obtener un intradós muy irregular cuya 
forma definitiva se perfeccionaba con una gruesa capa de mortero. En cambio, las dovelas más especializadas generan, lógicamente, un número menor de formas de la sección transversal, ya que están talladas con una forma específica para disponerse de un modo concreto.

Resulta interesante observar que con todos los tipos de dovelas se puede generar la forma recta, que es la morfología más común según los datos obtenidos. Cabe señalar este hecho, pues la forma recta de la sección transversal no es $a$ priori la más sencilla, ya que requiere de una planificación previa de la inclinación de la bóveda. Que esta forma sea la más común y que, además, las dovelas más especializadas tiendan a perfeccionarla, podría tener una razón simbólica derivada de la tendencia a imitar el espacio interior de la casa tradicional maya. El estudio de la evolución temporal de la bóveda nos ha permitido observar que los avances en la tecnología constructiva que se producen durante varios siglos en la arquitectura maya clásica perfeccionan la imagen interior que rememora la arquitectura doméstica de estructura de madera y cubierta vegetal.

\section{Conclusiones}

El estudio de la forma y la talla de las dovelas nos ofrece un punto de vista privilegiado para poder realizar una investigación en profundidad sobre la bóveda maya. El análisis comparativo de los datos tomados en campo nos ha permitido proponer una clasificación preliminar de los tipos de dovelas según su forma y grado de labra. Este aspecto constructivo determina en muchos casos las características formales de las bóvedas y es clave para estudiar las diferentes variantes regionales de la bóveda maya.

Una de las principales ventajas de la técnica de la bóveda por avance de hiladas es que admite piedras sin trabajar. Sin embargo, aunque al inicio los mayas aprovecharon esta ventaja, más tarde adquirieron conocimientos avanzados de estereotomía que les permitieron diseñar diferentes tipos de dovelas especializadas, planificar previamente la forma de las bóvedas y obtener superficies interiores lisas y regulares que sólo requerían una fina capa de estuco como acabado. A partir de los resultados obtenidos podemos afirmar que la evolución tecnológica en la arquitectura maya se produce con una clara intención de ahorro de piedra tallada. La mejora de la capacidad resistente de los rellenos permitió en algunos casos, especialmente en la arquitectura Puuc, reducir los sillares de los muros y las dovelas de las bóvedas al máximo, hasta convertirlas en lo que podría considerarse un encofrado permanente del relleno.

Como conclusión, cabe señalar que el análisis comparativo de las características de las bóvedas de diferentes áreas geográficas, considerando el factor temporal, puede contribuir al avance del conocimiento de las relaciones territoriales y la historia cultural de la civilización maya. Además, el estudio de la arquitectura maya desde el punto de vista constructivo resulta clave para la conservación ac- 
tual de este patrimonio cultural, pues permite evaluar los procesos de deterioro que le afectan y su situación estructural, así como diseñar las estrategias de excavación y restauración más adecuadas en cada caso.

\section{Bibliografía}

Andrews, George F.

1989 Comalcalco. Tabasco, Mexico. Maya art and architecture. Lancaster: Labyrinthos.

1995 Architecture of the Puиc Region and the Northern Plains Area. Lancaster: Labyrinthos (Pyramids and Palaces, Monsters and Masks. The Golden Age of Maya Architecture, 3 vols.).

Coe, William R.

1990 Excavations in the Great Plaza, North Terrace and North Acropolis of Tikal. Philadelphia: University of Pennsylvania Museum of Archaeology and Anthropology (Tikal Report, 14).

Gendrop, Paul

1983 Los estilos Río Bec, Chenes y Puuc. México: Universidad Nacional Autónoma de México.

Gerhardt, John C.

1988 Excavations al Cuello, Belize, 1987: A Preliminary Summary. New Jersey: Rutgers University, Archaeology Program.

Gilabert Sansalvador, Laura

2015 "La bóveda maya y su relación con otras culturas milenarias", América: cultura visual y relaciones artísticas, pp. 407-416, R. López Guzmán, Y. Guasch Marí y G. Romero Sánchez (eds.). Granada: Universidad de Granada. < https://test. andaluciayamerica.com/wp-content/uploads/2018/06/America_Cultura_Visual.pdf $>$.

2018 "La bóveda en la arquitectura maya", tesis de doctorado en Arquitectura. Valencia: Universitat Politècnica de València. <http:/hdl.handle. net/10251/114768>.

Hansen, Richard D.

1998 "Continuity and Disjunction: The Pre-Classic Antecedents of Classic Maya Architecture", Function and Meaning in Classic Maya Architecture, pp. 49-122, Stephen D. Houston (ed.). Washington: Dumbarton Oaks.

Miller, Mary

1998 “A Design for Meaning in Maya Architecture”, Function and Meaning in Classic Maya Architecture, pp. 187-222, Stephen D. Houston (ed.). Washington: Dumbarton Oaks.

Sharer, Robert J. y Loa P. Traxler

2006 The Ancient Maya. Stanford: Stanford University Press. 
Smith, A. Ledyard

1950 Uaxactun, Guatemala: Excavations of 1931-1937. Washington: Carnegie Institution of Washington (Publication, 588).

1962 "The Corbeled Arch in the New World", The Maya and their Neighbors: Essays on Middle American Anthropology and Archaeology, pp. 202-221, C. L. Hay, R. L. Linton, S. K. Lothrop, H. L. Shapiro y G. C. Vaillant (eds.). Nueva York: D. Appleton-Century Company.

Valdés Gómez, Juan Antonio

1992 "El crecimiento de la civilización maya en el área central durante el Preclásico Tardío: una vista desde el Grupo H de Uaxactún”, U Tz’ib, 1 (2): 16-31.

1993 "Arquitectura y escultura en la Plaza Sur del Grupo H, Uaxactún”, Tikal y Uaxactún en el Preclásico, pp. 96-122, Juan Pedro Laporte y Juan Antonio Valdés (eds.). México: Universidad Nacional Autónoma de México.

Laura Gilabert Sansalvador. Española. Doctora en Arquitectura por la Universitat Politècnica de València, es investigadora postdoctoral en el Instituto de Restauración del Patrimonio de la misma universidad. Sus principales áreas de interés son la arquitectura maya, la historia de la construcción, la conservación del patrimonio arquitectónico y la aplicación de las técnicas de levantamiento digital a los edificios históricos; desde 2010 forma parte del proyecto "La Blanca y su entorno". Su proyecto actual de investigación es "La arquitectura maya. Sistemas constructivos, estética formal y nuevas tecnologías" y entre sus publicaciones recientes se encuentran "La bóveda maya y su relación con otras culturas milenarias", "El arco urbano en la arquitectura maya" y "Los morillos como estructura auxiliar en el proceso constructivo de las bóvedas mayas”, estas dos últimas en coautoría.

gilabert.laura@gmail.com 